\title{
GAMBARAN EFEKTIFITAS PENYULUHAN DENGAN MEDIA POSTER DAN PHANTOM GIGI TERHADAP TINGKAT PENGETAHUAN TENTANG CARA MENYIKAT GIGI YANG BAIK DAN BENAR PADA SISWA/I KELAS IV SDN 065015 KEMENANGAN TANI
}

\author{
Netty Jojor Aritonang, Relintan Purba \\ Jurusan Keperawatan Gigi Poltekkes Kemenkes Medan
}

\begin{abstract}
Abstrak
Pengetahuan merupakan hasil dari tahu, terhadap suatu objek. Penyuluhan dilakukan dengan menyebarkan pesan menanamkan keyakinan, sehingga masyarakat sadar, tahu, dan mengerti. Penyuluhan dapat dilakukan dengan menggunakan media atau alat peraga/bantu. Media adalah alat atau sarana yang digunakan untuk menyampaikan pesan dari komunikator kepada khalayak.Penelitian ini bertujuan untuk mengetahui gambaran efektifitas penyuluhan dengan media poster dan phantom gigi terhadap tingkat pengetahuan tentang cara menyikat gigi yang baik dan benar pada siswa/I kelas IV SDN 065015. Jenis penelitiannya adalah deskriptif dengan metode survey, dengan populasi sampel kelas IV yang berjumlah 36 sampel. Berdasarkan penelitian yang telah dilakukan, diketahui bahwa tingkat pengetahuan siswa/i dengan penyuluhan menggunakan media poster pada kategori baik sebanyak 18 orang (50\%), kategori sedang sebanyak 10 orang $(27,8 \%)$ dan kategori buruk sebanyak 8 orang $(22,2 \%)$. Gambaran tingkat pengetahuan siswa/i dengan penyuluhan menggunakan media phantom gigi pada kategori baik sebanyak 27 orang (75\%), kategori sedang sebanyak 6 orang (16,7\%) dan kategori buruk sebanyak 3 orang (8,3\%).Dapat disimpulkan bahwa penggunaan media phantom gigi sebagai alat peraga dalam melakukan penyuluhan lebih efektif dibanding dengan penggunaan media poster. Hal ini berarti bahwa dalam proses pendidikan, benda asli mempunyai intensitas yang paling tinggi untuk mempersepsi bahan pendidikan/pengajaran.
\end{abstract}

Kata Kunci : Efektifitas Penyuluhan, Media, Pengetahuan

\section{PENDAHULUAN}

Kesehatan merupakan hal yang sangat penting bagi setiap manusia untuk dapat melakukan berbagai aktivitas baik secara fisik, mental dan kesejahteraan sosial secara lengkap dan bukan hanya sekedar tidak mengidap penyakit atau kelemahan (WHO 2009).Kesehatan gigi dan mulut merupakan bagian dari kesehatan tubuh yang tidak dapat dipisahkan satu dengan lainnya. Kesehatan gigi dan mulut akan mempengaruhi kesehatan tubuh keseluruhan. Gigi merupakan salah satu bagian tubuh yang berfungsi untuk mengunyah, berbicara dan mempertahankan bentuk muka. Berdasarkan Riskesdas (Riset Kesehatan Dasar) 2013 sebanyak 93,8\% menyikat gigi setiap hari dan sebanyak $97,7 \%$ berperilaku tidak benar menyikat gigi. Hal ini menunjukkan bahwa adanya pengetahuan menyikat gigi yang masih kurang dimasyarakat.

Menyikat gigi secara teratur dapat membantu mengurangi pembentukan plak gigi.Mengurangi konsumsi makanan dan minuman yang mengandung sukrosa juga merupakan langkah pencegahan kerusakan gigi. Kontrol kesehatan gigi secara berkala merupakan salah satu langkah menjaga kesehatan gigi (Syafrudin dkk,2011) Menyikat gigi adalah rutinitas kita sehari-hari. Bagian sikat gigi ini merupakan barang tambahan yang disia-siakan dalam kehidupan kita sehari-hari.Sikat gigi tidak bisa menghilangkan karang gigi tapi ia bisa mencegah hilangnya lapisan tipis yang melekat pada gigi sebelum ia berubah menjadi karang gigi. Tidak banyak orang menyadari bahwa sikat gigi itu partner yang sangat aktif untuk pasangan sikat dan pasta gigi.Inilah bahan tambahan yang paling banyak dilalaikan.Membeli sikat yang bagus dan menggunakannya secara benar merupakan suatu tindakan yang sangat baik (Srigupta A, 2004).Dalam mengajar anak untuk menggosok gigigigi mereka, tujuannya haruslah memberi instruksi dan mendorong semangat mereka untuk mengeluarkan semua debris dan plak dari semua permukaan gigi yang dapat dijangkau. (Andlaw R.J)Menurut teori Edgar Dale dalam buku Notoatmodjo 2003, menyatakan hasil belajar seseorang diperoleh melalui pengalaman langsung, dan melalui benda tiruan. Pengalaman langsung dan melalui benda tiruan akan memberikan informasi dan gagasan yang lebih banyak daripada menggunakan lambang kata-kata. Dimana penggunaan alat peraga dapat merangsang imajinasi anak dan memberikan kesan serta memberikan motivasi yang tinggi.Poster termasuk kedalam bentuk tulisan.Poster adalah karya seni atau desain grafis yang memuat 
komposisi gambar dan huruf diatas kertas berukuran besar.Poster umumnya bersifat mengajak masyarakat.Phantom gigi termasuk kedalam alat peraga benda tiruan.Phantom gigi manusia berfungsi untuk latihan demontrasi perlindungan mulut dan pengajaran klinis secara relatif.Model rahang gigi ini terdiri dari gusi, gigi, lidah, dan langit-langit. Alat ini menunjukkan bentuk gigi dan cara membersihkan rongga mulut dan perlindungan mulut. Dari survey awal yang dilakukan oleh peneliti pada siswa/I SDN 065015 Kemenangan Tani, pengetahuan tentang cara menyikat gigi yang baik dan benar masih rendah.

Berdasarkan hal diatas, maka peneliti tertarik untuk melakukan penelitian bagaimana "Gambaran Efektifitas Penyuluhan Dengan Media Poster dan Phantom Gigi Terhadap Tingkat Pengetahuan Tentang Cara Menyikat Gigi Yang Baik Dan Benar Pada Siswa/I Kelas IV SD Negeri 065015 Kemenangan Tani JL.Jamin Ginting Km 12 Medan"

\section{Tujuan Penelitian}

Untuk mengetahui Bagaimanakah gambaran efektifitas penyuluhan denganmedia poster dan phantom gigi terhadap tingkat pengetahuan tentang cara menyikat gigi yang baik dan benar pada siswa/I kelas IV SDN 065015 Kemenangan Tani Jl.Jamin Ginting Km 12.

\section{Manfaat Penelitian}

1. Penelitian ini digunakan sebagai tambahan pengetahuan dan wawasan siswa-siswi tentang cara menyikat gigi

2. Hasil penelitian ini diharapkan dapat menambah wawasan dan ilmu pengetahuan bagi pihak sekolah SD Negeri 065015 Kemenangan Tani JL.Jamin Ginting Km 12 Medan.

3. Hasil penelitian ini dapat digunakan sebagai bahan referensi bagi peneliti selanjutnya khususnya Jurusan Keperawatan Gigi Poltekkes Kemenkes Medan.

4. Untuk menambah wawasan, pengetahuan dan pengalaman bagi peneliti untuk menerapkan ilmu yang diperoleh.

\section{METODE PENELITIAN}

\section{Jenis dan Desain Penelitian}

Dalam penelitian ini, jenis penelitian yangdilakukan adalah jenis penelitian deskriptif dengan metode survey yang bertujuan untuk mengetahui gambaran efektifitas penyuluhan dengan media poster dan phantom gigi terhadap tingkat pengetahuan tentang cara menyikat gigi yang baik dan benar.

\section{POPULASI DAN SAMPEL}

Populasi adalah keseluruhan subjek penelitian (Arikunto S, 2006).Yang menjadi populasi dalam penelitian ini adalah siswa kelas IV SDN 065015 Kemenangan Tani JL.Jamin Ginting Km.12 Medan yang berjumlah sebanyak 36 orang.Menurut Arikunto S, 2006 mengatakan apabila subjeknya kurang dari 100, lebih baik diambil semua sehingga penelitiannya merupakan penelitian populasi. Tetapi, jika jumlah subjeknya besar, dapat diambil antara 10-15\% atau 20-25\% atau lebih.Maka sampel dalam penelitian ini adalah seluruh jumlah populasi yaitu sebanyak 36 orang.

\section{HASIL DAN PEMBAHASAN}

\section{Hasil Penelitian}

Data yang dikumpulkan adalah hasil penelitian yang telah dilakukan terhadap siswa/i kelas IV SDN 065015 Kemenangan Tani.Pengumpulan data dilakukan dengan penyuluhan dengan media poster dan phantom dan pembagian kuesioner kepada sasaran yang menjadi sampel. Setelah keseluruhan data terkumpul, maka dilakukan analisa data dengan cara membuat tabel distribusi frekuensi untuk masing masing variabel. Kemudian dilakukan pengolahan data dengan menggunakan skala ordinal.

Tabel 4.1. Distribusi Frekuensi Gambaran Efektifitas Penyuluhan dengan Media Poster Terhadap Tingkat Pengetahuan Tentang Cara Menyikat Gigi yang Baik dan Benar pada siswa/i kelas IV SDN 065015 Kemenangan Tani.

\begin{tabular}{cccc}
\hline No. & $\begin{array}{c}\text { Kategori Tingkat } \\
\text { pengetahuan }\end{array}$ & $\begin{array}{c}\text { Jumlah } \\
(\mathbf{n})\end{array}$ & $\begin{array}{c}\text { Persentase } \\
(\boldsymbol{\%})\end{array}$ \\
\hline 1 & Baik & 18 & 50 \\
2 & Sedang & 10 & 27,8 \\
3 & Buruk & 8 & 22,2 \\
\hline & Total & $\mathbf{3 6}$ & $\mathbf{1 0 0}$ \\
\hline
\end{tabular}

Dari tabel diatas, dapat dilihat bahwa persentase tingkat pengetahuan siswa/i tentang gambaran efektifitas penyuluhan dengan menggunakan media poster berada dalam kategori baik, yaitu sebanyak 18 orang (50\%), kategori sedang sebanyak 10 orang $(27,8 \%)$, dan kategori buruk sebanyak 8 orang $(22,2 \%)$.

Tabel 4.2 Distribusi Frekuensi Gambaran Efektifitas Penyuluhan dengan Phantom Gigi Terhadap Tingkat Pengetahuan Tentang Cara Menyikat Gigi yang Baik dan Benar pada siswa/i kelas IV SDN 065015 Kemenangan Tani.

\begin{tabular}{cccc}
\hline No. & $\begin{array}{c}\text { Kategori Tingkat } \\
\text { Pengetahuan }\end{array}$ & $\begin{array}{c}\text { Jumlah } \\
(\mathbf{n})\end{array}$ & $\begin{array}{c}\text { Persentase } \\
(\mathbf{\%})\end{array}$ \\
\hline 1 & Baik & 27 & 75 \\
2 & Sedang & 6 & 16,7 \\
3 & Buruk & 3 & 8,3 \\
\hline & Total & $\mathbf{3 6}$ & $\mathbf{1 0 0}$ \\
\hline
\end{tabular}

Dari tabel diatas, dapat dilihat bahwa persentase tingkat pengetahuan siswa/i tentang gambaran efektifitas penyuluhan menggunakan media phantom gigi berada dalam kategori baik, yaitu sebanyak 27 orang (75\%), kategori sedang 6 orang $(16,7 \%)$, dan kategori buruk 3 orang $(8,3 \%)$. 


\section{Pembahasan}

Penelitian ini menggunakan sampel sebanyak 36 orang siswa/i kelas IV SDN 065015 Kemenangan Tani. Tingkat pengetahuan siswa/i diukur berdasarkan pembagian kuesioner yang berisikan 12 pertanyaan, Berdasarkan penelitian yang telah dilakukan, diketahui bahwa tingkat pengetahuan siswa/i dengan penyuluhan menggunakan media poster pada kategori baik sebanyak 18 orang $(50 \%)$, kategori sedang sebanyak 10 orang $(27,8 \%)$ dan kategori buruk sebanyak 8 orang $(22,2 \%)$.Gambaran tingkat pengetahuan siswa/i dengan penyuluhan menggunakan media phantom gigi pada kategori baik sebanyak 27 orang (75\%), kategori sedang sebanyak 6 orang $(16,7 \%)$ dan kategori buruk sebanyak 3 orang $(8,3 \%)$.

Pengetahuan adalah informasi yang telah dikombinasikan dengan pemahaman dan potensi untuk menghendaki yang lantas melekat dibenak seseorang.Pada umumnya pengetahuan memiliki kemampuan prediktif terhadap sesuatu sebagai hasil pengenalan atas suatu pola.Seseorang memperoleh pengetahuan melalui penginderaan terhadap objek tertentu.Pengetahuan diperoleh sebagai akibat stimulus yang ditangkap panca indera. Pengetahuan bisa diperoleh secara alami maupun secara terencana yaitu melalui proses pendidikan. Pengetahuan merupakan ranah yang sangat penting untuk terbentuknya tindakan. (Budihardo, 2010)

Penyuluhan adalah ilmu sossial yang mempelajari sistem dan proses perubahan pada individu serta masyarakat agar dapat terwujud perubahan yang lebih baik sesuai yang diharapkan. (Setiana, 2005)

Penyuluhan dapat dilakukan dengan berbagai metode bagi individu, kelompok dan massa(public). Metode pendidikan bagi individu dapat berupa bimbingan dan penyuluhan (guidance dan counceling) serta interview (wawancara).

Media adalah alat atau sarana yang digunakan untuk menyampaikan pesan dari komunikator kepada khalayak.

Poster merupakan media publikasi yang terdiri atas tulisan, gambar ataupun kombinasi antar keduanya dengan tujuan memberikan informasi kepada khayalak ramai. Poster biasanya dipasang ditempat-tempat umum yang dinilai strategis seperti sekolah, kantor, pasar, mall dan tempat-tempat keramaian lainnya. Poster umumnya bersifat mengajak masyarakat.

Penyampaian pesan dengan media poster bertujuan untuk mengajak atau menghimbau masyarakat untuk melakukan sesuatu seperti yang telah dituliskan dan digambarkan didalam poster tersebut. Phantom gigi termasuk kedalam alat peraga benda tiruan.Phantom gigi manusia berfungsi untuk latihan demontrasi perlindungan mulut dan pengajaran klinis secara relatif.

Penggunaan media alat peraga merupakan implementasi salah satu prinsip proses pendidikan. Alat peraga sangat membantu didalam melakukan penyuluhan agar pesan-pesan kesehatan dapat disampaikan dengan lebih jelas, dan sasaran dapat menerima pesan tersebut dengan jelas dan tepat pula. (Notoatmodjo, 2003)
Hasil penelitian menunjukkan bahwa penggunaan media phantom gigi sebagai alat peraga dalam melakukan penyuluhan lebih efektif dibanding dengan penggunaan media poster.Hal ini berarti bahwa dalam proses pendidikan, benda asli mempunyai intensitas yang paling tinggi untuk mempersepsibahan pengajaran.

\section{SIMPULAN DAN SARAN}

\section{Simpulan}

Berdasarkan hasil yang telah diuraikan penulis menarik kesimpulan tentang gambaran efektifitas penyuluhan dengan media poster dan phantom gigi terhadap tingkat pengetahuan tentang cara menyikat gigi yang baik dan benar pada siswa/i kelas IV SDN 065015 Kemenangan tani sebagai berikut :

1 Pengetahuan siswa/i tentang gambaran efektifitas penyuluhan dengan menggunakan media poster berada dalam kategori baik, yaitu sebanyak 18 orang $(50 \%)$, kategori sedang sebanyak 10 orang $(27,8 \%)$, dan kategori buruk sebanyak 8 orang $(22,2 \%)$.

2 Pengetahuan siswa/i tentang gambaran efektifitas penyuluhan menggunakan media phantom gigi berada dalam kategori baik, yaitu sebanyak 27 orang $(75 \%)$, kategori sedang sebanyak 6 orang $(16,7 \%)$, dan kategori buruk 3 orang $(8,3 \%)$.

3 Dari kedua media yang diteliti media yang paling efektif adalah dengan media alat peraga phantom gigi dengan jumlah kategori baik sebanyak 27 orang $(75 \%)$ sehingga phantom gigi sebagai alat peraga/bantu dalam melakukan penyuluhan lebih efektif untuk digunakan meningkatkan pengetahuan siswa/i.

\section{Saran}

1 Kepada pihak sekolah agar dapat bekerja sama dengan instansi terkait dalam memberikan penyuluhan tentang cara menyikat gigi yang baik dan benar melalui program UKGS kepada anak-anak terutama dengan menggunakan media atau alat peraga/bantu.

2 Kepada guru dan orang tua murid agar dapat memberikan perhatian yang lebih besar dan mendidik anak-anak tentang cara menyikat gigi yang baik dan benar.

3 Kepada siswa/i SDN 065015 kemenangan tani supaya dapat menjaga kebersihan gigi dan mulut agar terhindar dari penyakit gigi dengan menyikat gigi 2 kali sehari (pagi setelah sarapan, malam sebelum tidur) dan juga memeriksakan kesehatan gigi dan mulut kedokter gigi minimal 6 bulan sekali.

\section{DAFTAR PUSTAKA}

Arikunto S. 2006. Prosedur Penelitian Rineka Cipta : Jakarta

Andlaw R.J, 1992. Perawatan Gigi Anak. Widya Medika : Jakarta

Budihardo.2010. Pendidikan Kesehatan Gigi dan Mulut. Rineka Cipta: Jakarta 
Herijulianti.2002. Pendidikan Kesehatan Jakarta

Notoatmodjo. 2003. Ilmu Kesehatan Masyarakat .Rineka Cipta : Jakarta

Notoatmodjo, 2005. Promosi Kesehatan. Rineka Cipta : Jakarta

Notoatmodjo, 2010.Promosi Kesehatan Teori \&Aplikasi Edisi Revisi. Rineka Jakarta

Notoatmodjo, 2012.Promosi Kesehatan. Cipta : Jakarta

Pintauli, S dan T Hamada. 2012. Menuju Mulut Sehat. USU Press : Medan

Panjaitan, M 1997.Ilmu Pencegahan Karies Press: Medan

Gigi. USU
Gigi.EGC : Syafrudin, dkk. 2011. Untaian Materi Penyuluhan KIA-Cara menggosok gigi Trans Info Media : Yogyakarta

Srigupta A. 2004. Perawatan Gigi dan Mulut.

Perpustakaan Nasional : Jakarta

https://id.m.wikipedia.org/wiki/poster

http://gusdanela.blogspot.co.id/2014/02/pengertian-mediamenurut-beberapa-ahli.html

(http://distributor-kursiroda.blogspot.co.id/2015/12/torso gigi manusia-model gigi-phantom-gigiperaga.html)

http://manfaat daunbuah.blogspot.co.id/2014/11/manfaat gosok - gigi - dan - cara - menggosoknya

http:// ciricara.com/2015/01/09/manfaat - menyikat - gigi - secara - teratur. 